\title{
HUSBAND SUPPORT REDUCES ANXIETY IN PRE-MENOPAUSE WOMEN
}

\author{
Hepti Widia Ningsih, Yuli Isnaeni
}

Study Program of Midwivery, Universitas ‘Aisyiyah Yogyakarta

\begin{abstract}
Background: The potential effect of stress on menopause symptoms is of importance to understand: midlife is often a highly stressful time for women, with many major life events coinciding with one another, such as parental death, children leaving home, and divorce. Previous research suggests that a strong social network and higher levels of social support throughout the menopausal transition may reduce menopause symptom frequency and severity. This study aimed to examine the effect of husband support in reducing anxiety in pre-menopause women.

Subjects and Method: This was a cross sectional study. The study was conducted in Sleman, Yogyakarta, Indonesia, in May 2019. A sample of 60 premenopausal women aged 45-50 years was selected for this study by simple random sampling. The dependent variable was anxiety. The independent variable was husband support. The data were collected by questionnaire and analyzed by Chi square.

Results: Strong husband support reduced the risk of anxiety in premenopausal women $(\mathrm{OR}=0.13 ; 95 \% \mathrm{CI}=0.03$ to $0.50 ; \mathrm{p}=0.001)$.

Conclusion: Strong husband support reduces the risk of anxiety in premenopausal women.

Keywords: husband support, anxiety, premenopause

Correspondence:

Hepti Widia Ningsih. Study Program of Midwivery, Universitas 'Aisyiyah Yogyakarta. Jl. Siliwangi 63 Sleman, Yogyakarta, Indonesia. Email: hepti_widia@yahoo.com. Mobile: +6285729442615 .
\end{abstract}

